\title{
Implications of recent epidemiologic studies for the linear nonthreshold model and radiation protection.
}

DOI:

10.1088/1361-6498/aad348

\section{Document Version}

Accepted author manuscript

Link to publication record in Manchester Research Explorer

\section{Citation for published version (APA):}

Shore, R., Beck, H., Boice, J. D., Caffrey, E., Davis, S., Grogan, H., Mettler, F., Preston, J., Till, J., Wakeford, R., Walsh, L., \& Dauer, L. (2018). Implications of recent epidemiologic studies for the linear nonthreshold model and radiation protection. Journal of Radiological Protection, 38(3), 1217-1233. https://doi.org/10.1088/13616498/aad348

\section{Published in:}

Journal of Radiological Protection

\section{Citing this paper}

Please note that where the full-text provided on Manchester Research Explorer is the Author Accepted Manuscript or Proof version this may differ from the final Published version. If citing, it is advised that you check and use the publisher's definitive version.

\section{General rights}

Copyright and moral rights for the publications made accessible in the Research Explorer are retained by the authors and/or other copyright owners and it is a condition of accessing publications that users recognise and abide by the legal requirements associated with these rights.

\section{Takedown policy}

If you believe that this document breaches copyright please refer to the University of Manchester's Takedown Procedures [http://man.ac.uk/04Y6Bo] or contact uml.scholarlycommunications@manchester.ac.uk providing relevant details, so we can investigate your claim.

\section{OPEN ACCESS}




\section{Implications of recent epidemiologic studies for the linear nonthreshold model and radiation protection}

To cite this article before publication: Roy Shore et al $2018 \mathrm{~J}$. Radiol. Prot. in press https://doi.org/10.1088/1361-6498/aad348

\section{Manuscript version: Accepted Manuscript}

Accepted Manuscript is "the version of the article accepted for publication including all changes made as a result of the peer review process, and which may also include the addition to the article by IOP Publishing of a header, an article ID, a cover sheet and/or an 'Accepted Manuscript' watermark, but excluding any other editing, typesetting or other changes made by IOP Publishing and/or its licensors"

This Accepted Manuscript is @ 2018 IOP Publishing Ltd.

During the embargo period (the 12 month period from the publication of the Version of Record of this article), the Accepted Manuscript is fully protected by copyright and cannot be reused or reposted elsewhere.

As the Version of Record of this article is going to be / has been published on a subscription basis, this Accepted Manuscript is available for reuse under a CC BY-NC-ND 3.0 licence after the 12 month embargo period.

After the embargo period, everyone is permitted to use copy and redistribute this article for non-commercial purposes only, provided that they adhere to all the terms of the licence https://creativecommons.org/licences/by-nc-nd/3.0

Although reasonable endeavours have been taken to obtain all necessary permissions from third parties to include their copyrighted content within this article, their full citation and copyright line may not be present in this Accepted Manuscript version. Before using any content from this article, please refer to the Version of Record on IOPscience once published for full citation and copyright details, as permissions will likely be required. All third party content is fully copyright protected, unless specifically stated otherwise in the figure caption in the Version of Record.

View the article online for updates and enhancements. 
MEMORANDUM: Implications of Recent Epidemiologic Studies for the Linear Nonthreshold Model and Radiation Protection

RE Shore ${ }^{\text {la }}$, HL Beck ${ }^{2}$, JD Boice $\mathrm{Jr}^{3}$, EA Caffrey ${ }^{4}, \mathrm{~S} \mathrm{Davis}^{5}$, HA Grogan ${ }^{6}$, FA Mettler $\mathrm{Jr}^{7}$, RJ Preston ${ }^{8}$, JE Till $^{9}$, R Wakeford ${ }^{10}$, L Walsh $^{11}$, LT Dauer $^{12,13}$

${ }^{1}$ New York University School of Medicine, New York, New York; and Radiation Effects Research Foundation (retired), Hiroshima, Japan

${ }^{2}$ U.S. Department of Energy (retired), New York, New York

${ }^{3}$ National Council on Radiation Protection and Measurements, Bethesda, Maryland; and Vanderbilt University, Nashville, Tennessee

${ }^{4}$ Radian Scientific, Huntsville, Alabama

${ }^{5}$ Fred Hutchinson Cancer Research Center, Seattle, Washington

${ }^{6}$ Cascade Scientific, Bend, Oregon

${ }^{7}$ University of New Mexico, Albuquerque, New Mexico

${ }^{8}$ U.S. Environmental Protection Agency, Research Triangle Park, North Carolina

${ }^{9}$ Risk Assessment Corporation, Neeses, South Carolina

${ }^{10}$ University of Manchester, Manchester, UK

${ }^{11}$ University of Zurich, Zurich, Switzerland

${ }^{12}$ Memorial Sloan Kettering Cancer Center, New York, New York

${ }^{13}$ The National Council on Radiation Protection and Measurements (NCRP) convened Scientific Committee SC 1-25 of experts to review recent epidemiologic studies of low-LET radiation, primarily at low doses or low dose rates, and evaluate whether the new observations provide support for the LNT model as used in radiation protection today. The NCRP Committee members are the authors of this memorandum.

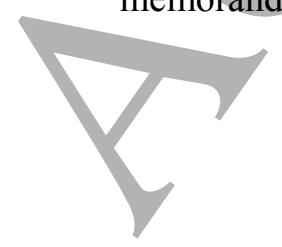


${ }^{a}$ Correspondence: Roy E. Shore, email hrshore@gmail.com. RE Shore and LT Dauer were Chair and Co-chair, respectively, of NCRP Scientific Committee SC 1-25 that produced NCRP Commentary No. 27.

Short title: NCRP: Epidemiologic Studies, the LNT Model and Radiation Protection

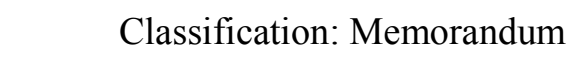




\section{Highlights}

- NCRP Commentary No. 27 focuses on low-dose or low dose-rate radiation exposures to evaluate if recent epidemiologic studies of solid cancer and leukemia risk support the use of the linear nonthreshold (LNT) model for radiation protection purposes.

- The Commentary critically reviews the strengths and weaknesses of the epidemiology, dosimetry and statistics of 29 studies of low-LET radiation with regard to quality and to degree of support for the LNT model.

- While uncertainties remain, NCRP judges that the epidemiologic evidence favors the application of the LNT dose-response model for low-level exposures as a prudent approach to radiation protection. 


\section{Abstract}

The recently published NCRP Commentary No. 27 evaluated the new information from epidemiologic studies as to their degree of support for applying the linear nonthreshold (LNT) model of carcinogenic effects for radiation protection purposes [1]. The aim was to determine whether recent epidemiologic studies of low-LET radiation, particularly those at low doses and/or low dose rates (LD/LDR), broadly support the LNT model of carcinogenic risk or, on the contrary, demonstrate sufficient evidence that the LNT model is inappropriate for the purposes of radiation protection. An updated review was needed because a considerable number of reports of radiation epidemiologic studies based on new or updated data have been published since other major reviews were conducted by national and international scientific committees. The Commentary provides a critical review of the LD/LDR studies that are most directly applicable to current occupational, environmental and medical radiation exposure circumstances. This Memorandum summarizes several of the more important LD/LDR studies that incorporate radiation dose responses for solid cancer and leukemia that were reviewed in Commentary No. 27. In addition, an overview is provided of radiation studies of breast and thyroid cancers, and cancer after childhood exposures. Non-cancers are briefly touched upon such as ischemic heart disease, cataracts, and heritable genetic effects. To assess the applicability and utility of the LNT model for radiation protection, the Commentary evaluated 29 epidemiologic studies or groups of studies, primarily of total solid cancer, in terms of strengths and weaknesses in their epidemiologic methods, dosimetry approaches, and statistical modeling, and the degree to which they supported a LNT model for continued use in radiation protection. Recommendations for how to make epidemiologic radiation studies more informative are outlined. The NCRP Committee recognizes that the risks from LD/LDR are small and uncertain. The Committee judged that the available epidemiologic data were broadly supportive of the LNT model and that at this time no alternative dose-response relationship appears more pragmatic or prudent for radiation protection purposes. 


\section{Introduction}

The U.S. National Council on Radiation Protection and Measurements (NCRP) convened a scientific committee of experts (SC 1-25) to address the appropriateness of applying the linear nonthreshold (LNT) model to radiation induced cancer for radiation protection purposes, as judged from recent radiation epidemiologic studies of low linear energy transfer (low-LET) radiation exposures. This Memorandum summarizes the key points of the resulting NCRP Commentary No. 27 [1].

The several national and international reviews $[2,3]$ in the last few decades of the health risks associated with exposure to low levels of ionizing radiation have generally considered that risk estimates based on human epidemiologic data on cancer induction at acute doses of $100 \mathrm{mGy}$ and above are more reliable than estimates based on data $<100 \mathrm{mGy}$, the low-dose region, or at any dose received at a low dose rate [4]. Nevertheless, data derived from studies of low dose or low dose-rate (LD/LDR) exposures provide a direct assessment of possible risks relevant to contemporary radiation exposures. For the purpose of Commentary No. 27, which focused on low-LET radiation, a low absorbed dose is defined as $<100 \mathrm{mGy}$ delivered acutely or accumulated over time, and a low absorbed dose rate is defined as $<5 \mathrm{mGy} \mathrm{h}^{-1}$ for any accumulated dose [4].

The shape of the dose-response relationship and the level of risk from LD/LDR exposures is not well defined for low-LET radiation because of the intrinsic uncertainties in epidemiologic and radiobiologic studies of possible effects. How these uncertainties are handled can influence actions taken regarding radiation protection guidance, medical practice, compensation programs, environmental contamination issues, technological advances, and communication of risk associated with low-level radiation exposure [5]. For over 40 years the LNT dose-response model has been used for practical and prudent guidance on ways to protect workers and the public from the potential harmful effects of low-LET radiation in balance with the beneficial, justified, and optimized uses of radiation. Though no model can be proven to be "correct" given the uncertainties inherent in the epidemiologic LD/LDR data, the primary question is whether the LNT model remains appropriate for radiation protection purposes. 
Around a decade ago, both the BEIR VII [3] and UNSCEAR [2] committees reviewed epidemiologic studies of cancer risk from low-LET irradiation, with a large fraction of the studies being based on acute exposures to moderate and high doses. A considerable number of results for updated or new cohorts, many of them with LD/LDR exposures, have been reported since then. The focus of NCRP Commentary No. 27 was on LD/LDR epidemiologic studies, but also included recent studies of Japanese atomic bomb survivors for comparison and as these relate to risks at acute low doses. The aim was to determine whether these epidemiologic studies broadly support the LNT model of carcinogenic risk or, on the contrary, demonstrate sufficient evidence that the LNT model is inferior to some other model for the purposes of radiation protection. The strength of epidemiologic support for the LNT model was evaluated for LD/LDR studies of the incidence of, or mortality from, solid cancer or leukemia. While it was recognized that different types of cancer have different dose-response relationships (and some cancers have not been consistently associated with radiation [2]) and that combining diverse cancers with different etiologies and cell types is not biologically optimal, the limited statistical power of data available for most specific cancer types required a pragmatic approach for radiation protection of using groupings of all solid cancers combined and leukemias (excluding chronic lymphocytic leukemia, "non-CLL leukemia"). Brief consideration was given to LD/LDR studies of thyroid, breast and childhood cancer. Non-cancers also are touched upon briefly: ischemic heart disease, cataracts, and heritable genetic effects.

\section{Study Reviews}

The studies selected for review focused on LD/LDR studies. The selection was by consensus of the Committee which included experts with a broad purview of the recent radiation epidemiology literature. The selection also was checked against recent comprehensive meta-analyses of such studies [6]. The studies consisted of relatively large cohorts with individual dosimetry and radiation dose-response risk coefficients for total solid cancer, individual cancers or non-CLL leukemia. Earlier reports containing redundant data were eliminated. Analyses of the Japanese Life Span Study of atomic bomb survivors and 
LD/LDR studies of exposed groups or tumor sites of special interest (fallout, in utero and early childhood exposures; breast cancer, thyroid cancer) also were included. Twenty-nine major studies were critically reviewed.. The critiques included an assessment of the quality of the epidemiology, dosimetry, and statistics of individual studies. The epidemiologic critiques included a characterization of the study dẹsign and study population, quality of the data available, data collection methodology and success/rates, the degree to which potential confounding variables or biases were assessed, and the quantitative results. The evaluation of the dosimetry of each study included the completeness and precision of the dose information (gamma, neutron and internal exposures) over time for worker studies, the quality of dose reconstruction for applicable studies such as environmental and medical, and the estimation and incorporation of dose uncertainties in determining the shape of the dose-response curve for LD/LDR studies [7]. Statistical evaluations considered whether the analytic methods were appropriate, whether the study considered statistical alternatives to a linear dose-response trend, and whether sensitivity analyses or other clarifying analyses were undertaken. Based on those considerations and on the observed dose-response results, the strength of the study's support for the LNT model as a basis for radiation protection was characterized. Several key studies of radiation and the mortality or incidence of solid cancer and non-CLL leukemia are summarized below.

\subsection{Life Span Study}

Although the Commentary focused primarily on LD/LDR studies [1], the Life Span Study (LSS) of the Japanese atomic bomb survivors was included as a comparison study. Of note, however, is that about twothirds $(\sim 68,000)$ of the LSS cohort received estimated colon doses $<100 \mathrm{mGy}$, i.e., low doses. The LSS cohort has provided important data because it is a fairly large cohort (86,661 survivors of all ages) with relatively accurate dosimetry [8], a wide dose range ( 0 to 4 Gy colon absorbed dose), over 50 years of highquality follow-up for mortality and cancer incidence, and over 1,000 excess cancer cases estimated to be associated with radiation exposure [9-11]. These features yield good statistical power and narrow confidence intervals (i.e., good precision) of risk estimates for aggregated groupings of all solid cancers 
and leukemia. A pure quadratic model for solid cancer provided a significantly poorer fit than a linear doseresponse model, although there was evidence of curvilinearity in these data $[9,10]$.

The most recent solid cancer mortality and incidence data provide some evidence for upward curvature in the dose response consistent with a linear-quadratic model. This implies a shallower, but still positive, dose-response slope at lower doses than at higher ones, although most notably for incidence data [9], this curvilinearity appeared to be confined to males; for females the dose response was essentially linear. The reasons for this sex difference in curvature are yet to be established, though it may partly have to do with divergent profiles of tumor types [9][12]In summary, the study continues to provide support for the use of a LNT model in radiation protection, with consideration that the slope may be lower though still positive at lower doses. However, unlike most other studies reviewed in NCRP Commentary No. 27, the LSS estimates the effects of a single, brief exposure which may not directly apply to protracted or highlyfractionated exposures.

\subsection{Worker Studies}

Radiation worker studies assess risks in worker groups who largely received low cumulative doses at low dose-rates, and these studies were used to address directly the appropriateness of the LNT model for low dose-rate exposures. Some of the studies have reasonably high statistical power, in part because substantial numbers of workers employed during the 1940s, 1950s and 1960s received cumulative doses over their working lives that were several hundred mGy. However, most studies have low, inadequate statistical power when considered alone because of mostly low cumulative doses, small numbers of workers or short lengths of follow-up. The pooling studies [13] and meta-analyses of studies of cohorts of radiation workers [6] provide increased statistical precision in the estimation of risk. Two of the more informative worker studies are summarized below.

INWORKS Study: The most informative study of pooled cohorts is the International Nuclear Workers Study (INWORKS) that included 308,000 workers from nuclear facilities in the United Kingdom, United States and France [13-18]. INWORKS examined mortality from various causes in relation to cumulative photon doses (mainly gamma radiation) from external sources, and the consortium expended 
considerable effort to improve and harmonize the dose estimates $[19,20]$. Although they estimated that photon dose uncertainties were small, intrinsic uncertainties remain, especially for workers in the 1940s and 1950s, such as "missed" film badge doses due to recording doses below the limit of detection as zero or recording doses below the limit of detection as the minimally detectable dose, and doses from neutron and internal exposures were not included [19]; these doses could be positively correlated with recorded photon doses leading to an overestimation of the slope of the dose-response. The reported mean cumulative colon dose to exposed workers from photons was $20.9 \mathrm{mGy}$. Estimated external photon dose to the colon was associated with mortality from all solid cancers combined, with an excess relative risk (ERR) $\mathrm{Gy}^{-1}$ of 0.47 , $90 \%$ confidence interval (CI) of 0.18 to 0.79 [13]. This risk estimate is greater than, but statistically compatible with, the solid cancer mortality ERR Gy ${ }^{-1}$ estimate of $0.35(95 \%$ CI $0.24,0.47)$ for the matched (on sex, age at initial exposure and attained age) risk from the LSS (see [6]). For solid cancers there was little evidence of nonlinearity ( $p=0.44$ ) or of a dose threshold. When the cumulative colon dose was restricted to $<100 \mathrm{mGy}$, a marginally significant dose response was calculated for all cancers excluding leukemia (ERR Gy ${ }^{-1}$ of $0.8,90 \%$ CI $\left.0.01,1.6\right)$ [13]. The recently published site-specific results [18] suggest some caution, however, when interpreting the combined solid cancer analyses because of statistically significant associations between radiation dose and mortality from specific cancers that have not previously been convincingly linked to radiation (testes, rectum, and peritoneum), and a positive association with radiation was reported for cancers that have been linked primarily to asbestos exposure (pleura and mesothelioma) which might occur for work around thermal insulation. These associations suggest there may be confounding in the data. INWORKS investigators also reported an association between the cumulative external photon dose to the red bone marrow (RBM) and mortality from non-CLL leukemia with an ERR Gy ${ }^{1}$ of $3.0(90 \%$ CI $1.2,5.2)[14]$.

Mayak Study: The Russian Mayak cohort of over 25,000 workers is of interest because of the high cumulative external doses received, mainly at low dose rates, by many workers during the early years of operations at this installation (mean cumulative colon dose from external sources of $354 \mathrm{mGy}$ ). About $80 \%$ of the annual doses for individuals were based on dosimetric measurements, the remainder from dose 
reconstructions; extensive work has been ongoing to improve these worker dose estimates [21, 22]. Estimated corrections were made to the early unfiltered film badges for the range of photon energies, angular responses and high-energy beta exposures, and neutron exposures were reconstructed [23]. Nonetheless, uncertainties in external doses remain, particularly for those employed in earlier years of operations, and the substantial doses possible from any intakes of plutonium add a further complication. Investigators reported statistically significant associations between external colon dose and mortality from all solid cancers excluding lung, liver and bone (i.e., these cancers at the major sites of plutonium deposition were excluded) and adjusting for plutonium exposure; the ERR Gy ${ }^{-1}$ was 0.12 (95\% CI: 0.03 to 0.21). When the analysis was restricted to workers with little potential for exposure to plutonium, the ERR $\mathrm{Gy}^{-1}$ became $0.19(95 \%$ CI $0.02,0.39)$ [24]. These risk estimates were less than the solid cancer mortality estimate of ERR Gy ${ }^{-1} 0.43(95 \%$ CI $0.30,0.56)$ for the matched risk in the LSS [6]. There was no statistical indication of nonlinearity $(p>0.5)$ although the degree of risk below several hundred mGy was uncertain [25]. For incidence of non-CLL leukemia the linear ERR Gy ${ }^{-1}$ estimate was 3.57 (90\% CI 1.55, 8.22) for cumulative external radiation dose to the red bone marrow (RBM), adjusted for plutonium exposure [26]. The linear-quadratic model fitted marginally better for non-CLL leukemia than the linear model $(p=0.11)$, and the pure linear and pure quadratic models fitted about equally well. New reports are planned based on extended follow-up and further improvements in the dosimetry, with dose uncertainties taken into account in the risk estimates $[21,22,27]$.

Summary of Worker Studies: Other worker studies reviewed included Japanese [28], Canadian [29], U.S. Mound [30] and U.S. Rocketdyne [31] nuclear workers, Russian Chernobyl clean-up workers [32], U.S. radiologic technicians [33], French uranium processing workers [34], Chinese medical x-ray workers [35] and U.S. atomic veterans [36]. Although the accuracy of the risk estimates is limited to various degrees by uncertainties in dosimetric and epidemiologic factors, the strongest nuclear worker studies lend support to the inference that an excess risk of cancer exists following exposure to mainly low doses received at low dose rates. The dose-response data are broadly supportive of an LNT model for radiation protection purposes, perhaps modified by a dose rate effectiveness factor (DREF). (A DREF $>1$ 
means the dose-response slope of the effect for low dose-rate exposures is smaller, by a factor of 1/DREF, than the slope of a study with higher acute doses, typically the LSS.) Further follow-up of these cohorts, along with additional cohorts within the Million Person Study, currently underway in the United States [37, 38], should, in the next few years, appreciably augment the information available on radiation-related cancer risks in groups of workers and consequently reduce the uncertainties in risk estimation after exposures at low dose rates $[39,40]$.

\subsection{Environmental Exposure Studies}

The worker studies are complemented by those on environmental exposures, of which several of the more important studies are summarized here.

Techa River Study: Between 1949 and 1956 the Russian Mayak nuclear weapons facility released radioactive waste into the Techa River and exposed approximately 30,000 residents living downstream to doses received at low dose rates from external sources of gamma rays and internally from ${ }^{137} \mathrm{Cs}$ and ${ }^{90} \mathrm{Sr}$. Considerable efforts have been made to develop individual dose reconstructions for residents (mean dose $35 \mathrm{mGy}$, range $\sim 0$ to $960 \mathrm{mGy}$ ) [41].The recent studies of the Techa River Cohort have found associations between radiation dose with incidence [42] or mortality [43] rates for solid cancers. For the 2,300 deaths from solid cancers the linear ERR Gy was $0.61(95 \%$ CI 0.04, 1.27) but the shape of the dose-response curve was unclear. For non-CLL leukemia incidence the ERR Gy ${ }^{-1}$ was $2.2(95 \%$ CI $0.8,5.4)$ and the linear model provided the best fit [44]. However, uncertainties in the dose reconstruction and cancer ascertainment limit inferences about the shape of the dose-response curves in relation to the LNT model. Further, the tendency for risk to increase with age-at-exposure, and the statistically significant excess of cancers of the uterine cervix, a site not convincingly linked to radiation, and of the esophagus, a site not usually predominant as a radiation effect, add caution to the interpretation of the results [42]. Analyses using improved dosimetry and updated follow-up are underway.

Chernobyl Thyroid Cancer Studies: New studies of cohorts of children in Ukraine and Belarus who had thyroid measurements of ${ }^{131}$ I activity shortly after the Chernobyl accident and subsequent systematic thyroid screening have added appreciably to our knowledge about thyroid cancer risk after protracted 
internal exposure. Both cohorts showed linear dose-response functions with little evidence of nonlinearity [45-47], though with an apparently lower risk per unit dose than seen in studies of children exposed to external radiation at fairly high dose rates [48]. The estimated thyroid doses are reasonably accurate though still uncertain [49], which lends support to a LNT interpretation following childhood exposures.

High Natural Background Radiation Area Studies: Studies of residents in areas of high natural background radiation have been conducted in Kerala, India and Yangiiang, China. The higher quality and larger of the two high natural background radiation studies, the Kerala study of cancer incidence, included 70,000 individuals and over 1,300 cancers from high-background or low-background radiation areas (Nair et al., 2009). The dosimetry was based on measurements of ambient levels within and near homes, coupled with estimated age/sex-specific average house-occupancy factors (mean/dose $161 \mathrm{mGy}$, range $\sim 0$ to $>700$ mGy) [50]. The investigators reported an ERR Gy ${ }^{-1}$ of $-0.13(95 \% \mathrm{CI}-0.58,0.46)$ for all cancer except leukemia [51], and there were too few leukemia cases to be informative. The Yangjiang study reported a positive, but nonsignificant, risk coefficient for mortality from all cancer except leukemia and liver cancer (ERR Gy ${ }^{-1} 0.19,95 \%$ CI $-1.9,3.0$ ) [52]; liver cancer mortality was excluded because it appeared to be confounded by geographic variations in diagnosing liver diseases and also the widespread prevalence of hepatitis viral infections. These studies are nominally more supportive of little or no effect after low doserate exposures rather than of the LNT model. However, the geographic regions associated with various levels of dose rate may also have variations in lifestyles and other risk factors besides radiation level which could serve to confound the inference regarding radiation effects. Furthermore, the substantial uncertainties in dosimetry, the weaknesses in cancer ascertainment in the regions under study (except perhaps in Kerala which has a cancer registry), and the wide confidence intervals on the risk estimates mean that results need to be interpreted with caution.

\subsection{Childhood Irradiation Studies}

Diagnostic medical exposures are typically partial body, and study results are subject to significant uncertainties including, but not limited to, poorly documented historical exposure data, limited organ dosimetry for organs other than the target organ, and potential biases because radiologic procedures are 
often administered for an existing health condition. Recent epidemiologic studies have involved populations who had received computed tomography (CT) scans during childhood when risk might be greater because individual CT doses were relatively high for diagnostic procedures (though still $<100 \mathrm{mGy}$ ) and children may be more radiosensitive to cancer induction than adults for some but not all cancer types [53]. The major studies were not limited to childhood exposures but included exposures at ages 0-21 [54] and 0-19 years [55]. A significant deficiency is that information on organ doses from CT examinations in the 1980s and 1990s is sparse and individual doses were not reconstructed in the primary studies [54, 55]. Most importantly, the CT studies suffered from potentially serious biases because the reasons for the examinations were not known, so they could not convincingly address confounding by indication (CT examinations more likely for those who have conditions that confer risk for cancer) and reverse causation (incipient malignancy not detected by the CT examination) $[53,56,57]$. Further studies have now documented the presence of those biases in cohorts receiving CT examinations [58-60], although the impact on results is not yet clear. The CT studies have reported large and essentially linear risk estimates. But, because of the weak dosimetry and potential for bias, the currently available CT epidemiologic study results are inconclusive for evaluating the LNT dose-response model.

The data on postnatal diagnostic $\mathrm{x}$-ray exposures from conventional radiography and childhood leukemia risk are considered inconclusive [61]. Although case-control studies of childhood cancer after diagnostic $\mathrm{x}$-ray exposure in utero, involving fetal doses of $\sim 10-50 \mathrm{mGy}$, are consistent with increased risk for leukemia and other childhood cancers, the interpretation of these studies is not straightforward [61, 62]. Studies of irradiation in childhood or adolescence and subsequent development of breast cancer generally support a linear dose response [53]. A recent pooled analysis of nine studies of external thyroid irradiation in childhood (primarily under age $15 \mathrm{y}$ ) and subsequent thyroid cancer showed a strong dose response, even over the range of 0 to $100 \mathrm{mGy}$, and little evidence of nonlinearity [48]. An analysis of solid cancer incidence among the Japanese atomic bomb survivors exposed before birth or during childhood showed a dose response with marginally significant upward curvature $(p=0.09)$, suggesting that the dose-response slope may be shallower in the low-dose range [63]. In general, the low dose data for children are sparse, 
often with limited dosimetry, so uncertainties are substantial. However, the data broadly support the LNT model, especially the data for breast and thyroid cancer.

\subsection{Diseases Classified as Tissue Reactions}

Most of the available data on noncancer radiation effects, which are generally considered to have dose thresholds rather than being stochastic in nature, have large associated uncertainties and limitations that provide only crude estimates of dose threshold values. Recent epidemiologic evidence, however, suggests the possibility that poorly understood radiobiological mechanisms associated with moderate doses or low dose rates may produce an increased risk of CVD [1, 64]. Studies of nuclear workers and other exposed groups provide an inconsistent picture of CVD risk, and most of them lack information on important potential confounding variables associated with lifestyle and medical risk factors (e.g., diabetes, obesity, smoking). Therefore, the NCRP committee considered the current evidence to be too weak and inconsistent to support a LNT model for CVD for the purposes of radiation protection.

Studies of cataracts in the atomic bomb survivors, Chernobyl clean-up workers and other studies have revealed minor lens opacities at doses lower than previously considered to be cataractogenic, but do not yet support an LNT interpretation or an estimate of a specific dose threshold value for effects from either acute or protracted exposures to the lens of the eye. Ophthalmologically detectable opacities are reported at doses of about 0.5 Gy and above, with large uncertainties below this dose, so the appropriateness of a linear, linear-quadratic or dose-threshold model is unresolved [64-66].

\section{Results of Study Evaluations}

Support by specific studies for any model required adequacy of the study components, which were classified as epidemiologic methods, dosimetric approaches, and statistical modeling. The NCRP Committee evaluated the epidemiologic, dosimetric and statistical components for 29 principal studies or groups of studies of cancer risk using judgments of "strong", "moderate", or "weak" for each component, with intermediate scores (e.g., "weak-to-moderate") also permitted. To summarize study adequacy, 17 
To support additional radiation epidemiology efforts to address the LNT model as used in radiation protection, the NCRP commentary [1] recommended a number of potentially profitable areas of focus for future research. Selected ones are provided here to stimulate further discussions.

Atomic Bomb Survivors: The low-dose data on solid cancer need to be examined in more detail to determine why the dose-response shapes differ between males (linear-quadratic) and females (linear) [9]. Low-dose risks of cardiovascular diseases and various clinical health endpoints also should be evaluated to the extent possible. An examination is needed of whether the LNT model applies to tumors of various organs or organ systems, insofar as statistical limitations permit, to evaluate the generality of the LNT 
model across tumor sites. Updated information on cancer risk among those exposed in utero and early childhood would help answer the question of whether risks for those two groups are different as well as provide estimates of risks at older ages for these groups. Innovative ways should be considered to facilitate the biomedical community's access to the large repository of blood, urine and tissue samples from individuals with a range of exposure levels, some who likely developed radiation-related diseases. Such collaborations would facilitate the identification of bioindicators of adverse factors that trigger disease development after irradiation and fill gaps in knowledge of how whole-body exposures to radiation cause human cancer and other diseases using this unique biosample repository.

Worker Studies: Much of the statistical power of these studies derives from those workers who have accumulated moderate doses of several hundred mGy over many years. Continuing follow-up of worker cohorts is a high priority, as much of the cancer incidence and mortality is yet to occur at older ages. Doses in the earliest years of operation tended to be highest but also had the greatest uncertainties because many dose recording technologies and procedures were less advanced than they are today. Therefore, more in-depth analysis of early exposures will be valuable to identify, and if possible remedy, any deficiencies in recorded doses. Issues of neutron exposures, internal exposures and "missed" photon doses need to be addressed further. Valid risk estimates depend upon reliable dose estimates, so this area should be pursued vigorously.

Environmental Radiation Studies: Environmental radiation study investigators should make efforts to reduce uncertainties in the individual reconstructed dose estimates and to account for the uncertainties in risk estimates. The Kerala and Yangjiang studies should increase efforts to improve cancer ascertainment and diagnosis and to closely examine sociodemographic, lifestyle and geographic factors that may affect the adequacy of cancer ascertainment and background risks. Collection and storage of biospecimens from strategically defined subgroups with relatively high estimates of cumulative dose, within environmentally exposed cohorts may be useful for future biodosimetry, molecular epidemiology and bioindicator studies. Other Future Directions: Better integration of dosimetry and epidemiology in study implementation and analysis is needed. Both shared and unshared uncertainties should be provided with the individual 


\section{Discussion}

The principal purpose of NCRP Commentary No. 27 [1] was to assess whether the LNT model is appropriate for the purposes of radiation protection given the new epidemiologic evidence available. Quantitative risk coefficients and dose-response relationships for solid cancers based on estimated individual doses have been reported for well over half a million individuals with low dose-rate exposures and mostly low cumulative doses from studies of radiation workers or of populations living in areas with elevated environmental radiation levels [6].

Strengths of the better LD/LDR studies include relatively good quality dosimetry, long follow-up, high rates of cohort mortality/morbidity ascertainment, large numbers of cancers and person-years at risk, attention to potential confounding variables, and proper analysis. Nevertheless, many individual low-dose studies have intrinsically insufficient statistical power and consequent low precision in risk estimation, in large part because the risk of cancer at very low doses is predicted to be very small and is therefore difficult to statistically distinguish from variations in background risk. Further the effect of slight variation in confounding factors has a much greater influence a low compared with higher doses. Conducting pooled studies [13] and meta-analyses $[6,72,73]$ has helped address the statistical power limitations, though more abundant data are needed. Both extended follow-up of the available cohorts and 
completion of the Million Person Study in the United States will augment the available information in the future $[37,74]$.

The NCRP Committee recognized that confounding by non-radiation risk factors for diseases of interest could bias study results and diminish consistency among studies. Many of the studies have attempted to address these issues. The analyses of nearly all studies have considered variations in risk by sex, attained age and often age at exposure. Several studies have directly evaluated or adjusted for the influence of possible confounding by medical radiation exposures $[43,75]$ or lifestyle factors (e.g., smoking) $[9,25,28,42,51,76]$. Other studies have employed indirect approaches to assess whether there might be biases associated with factors for disease risk [13, 29-31, 52, 77-80], and they have largely not reported evidence of confounding by smoking or other factors, although the influence of such factors at the lowest doses could not be completely discounted. A consideration related to this is that lifestyle or other disease risk factors will cause confounding only if their frequency (or intensity) varies consistently by dose.

Although several studies showed null/negative dose-response relations for solid cancer (Table 1) or provided only limited evidence of a positive association at doses under about $100 \mathrm{mGy}$ [32, 43], a variety of studies has shown elevated solid cancer occurrence in the low-dose range [6, 10, 13, 25, 48]. Eleven (38\%) studies provided moderate or strong support for the LNT model for radiation protection (Table 1), and other LD/LDR reports indicate dose-related elevations in leukemia risk [14, 26, 44, 81-83]. Thus, the weight of evidence continues to support the use of the LNT model for low doses and dose rates exposures.

NCRP Commentary No. 27 [1] evaluated recent epidemiologic studies as to whether they provided support for the continued use of the LNT model in radiation protection. The purview did not include, however, an evaluation of recent experimental radiation studies on mutations, cytogenetics, cells, and animals or mechanistic understanding which would complete the assessment $[4,84,85]$.

\section{Conclusions}


While the LNT model cannot be scientifically proven by epidemiologic evidence at very low doses or low dose rates, the preponderance of high-quality epidemiologic data is reasonably consistent with the LNT assumption. The current data are not precise enough to exclude models that differ from the LNT model, and there is evidence from some datasets that the slope of the dose response at low levels of exposure may be less than that at higher levels. The NCRP Commentary recognizes that the risks from a few tens of mGy are uncertain and are predicted to be very small. The NCRP judges, in accordance with other national and international scientific committees $[2,3,86]$, that the available epidemiologic evidence does not point to any alternate dose-response relationship that would be more pragmatic or prudent for radiation protection purposes than the LNT model. Therefore, NCRP concludes that, based on current epidemiologic data, the LNT model (perhaps with excess risk estimates reduced by a DREF) should continue to be used for radiation protection purposes [1]. 
Acknowledgements: Financial support was provided by the U.S. Nuclear Regulatory Commission (Grant NRC-HQ-60-14-G-0012) for the NCRP production of Commentary No. 27. The work was conducted independently of the sponsoring agency and does not necessarily reflect its views.

Conflicts of Interest: Richard Wakeford is a member of the Technical Working Party of the UK Compensation Scheme for Radiation-Linked Diseases and provides advice on radiological protection matters to the Tokyo Electric Power Company. Roy Shore and Julian Preston are members of the Lowdose Scientific Advisory Committee for the Electric Power Research Institute (EPRI), and Lawrence Dauer has contracts with EPRI. The respective authors attest that the associations had no influence on their work on this report. 


\section{REFERENCES}

[1] NCRP 2018 Implications of Recent Epidemiologic Studies for the Linear Nonthreshold Model and Radiation Protection, Commentary No. 27 (Bethesda, MD: National Council on Radiation Protection and Measurements)

[2] UNSCEAR 2008 Epidemiological studies of radiation and cancer. Effects of Ionizing Radiation Sources and Effects of Atomic Radiation, UNSCEAR 2006 Report (Scientific Annex A) vol 1 (New York: United Nations Scientific Committee on the Effects of Ionizing Radiation)

[3] NAS-NRC (National Academy of Sciences-National Research Council) 2008 Health Risks From Exposure to Low Levels of Ionizing Radiation: BEIR VII. Phase 2, 2006 (Washington, DC: The National Academies Press)

[4] NCRP 2015 Health effects of low doses of radiation: perspectives on integrating radiation biology and epidemiology, Commentary No. 24 (Bethesda, MD: National Council on Radiation Protection and Measurements)

[5] NCRP 2012 Uncertainties in the estimation of radiation risks and probability of disease causation, Report No. 171 (Bethesda, MD: National Council on Radiation Protection and Measurments)

[6] Shore R, Walsh L, Azizova T and Rühm W 2017 Risk of solid cancer in low dose-rate radiation epidemiological studies and the dose-rate effectiveness factor Int. J. Radiat. Biol. 93 1064-78

[7] Till J E, Beck H P, Grogan H A and Caffrey E A 2017 A review of dosimetry used in epidemiological studies considered to evaluate the linear no-threshold (LNT) dose-response model for radiation protection Int. J. Radiat. Biol. 93 1128-44

[8] Cullings H M, Grant E J, Egbert S D, Watanabe T, Oda T, Nakamura F, Yamashita T, Fuchi H, Funamoto S, Marumo K et al 2017 DS02R1: Improvements to atomic bomb survivors' input data and implementation of dosimetry system (DS02) and resulting changes in estimated doses Health Phys. 112 56-97 
[9] Grant E J, Brenner A, Sugiyama H, Sakata R, Sadakane A, Utada M, Cahoon E K, Milder C M, Soda M, Cullings H M et al 2017 Solid cancer incidence among the Life Span Study of atomic bomb survivors: 1958-2009 Radiat. Res. 187 513-37

[10] Ozasa K, Shimizu Y, Suyama A, Kasagi F, Soda M, Grant E J, Sakata R, Sugiyama H and Kodama K 2012 Studies of the mortality of atomic bomb survivors, Report 14, 1950-2003: an overview of cancer and noncancer diseases Radiat. Res. 177 229-43

[11] Hsu W-L, Preston D, Soda M, Sugiyama H, Funamoto S, Kodama K, Kimura A, Kamada N, Dohy H, Tomonaga M et al 2013 The incidence of leukemia, lymphoma and multiple myeloma among atomic bomb survivors: 1950-2001 Radiat. Res. 179 361-82

[12] Furukawa K, Misumi M, Cologne J B and Cullings H M 2016 A Bayesian semi-parametric model for radiation dose-response estimation Risk Analy. 36 1211-23

[13] Richardson D B, Cardis E, Daniels R D, Gillies M, O'Hagan J A, Hamra G B, Haylock R, Laurier D, Leuraud K, Moissonnier M et al 2015 Risk of cancer from occcupational exposure to ionising radiation: retrospective cohort study of workers in France, the United Kingdom, and the United States (INWORKS) Br. Med. J. 351 h5359

[14] Leuraud K, Richardson D B, Cardis E, Daniels R D, Gillies M, O'Hagan J A, Hamra G B, Haylock R, Laurier D, Moissonnier M et al 2015 Ionising radiation and risk of death from leukaemia and lymphoma in radiation-monitored workers (INWORKS): an international cohort study Lancet Haematol. 2 e276-e81

[15] Hamra G B, Richardson D B, Cardis E, Daniels R D, Gillies M, O'Hagan J, Haylock R, Laurier D, Leuraud K, Moissonnier M et al 2016 Cohort profile: the International Nuclear Workers Study (INWORKS) Int. J. Epidemiol. 45 693-99

[16] Laurier D, Richardson D B, Cardis E, Daniels R D, Gillies M, O'Hagan J, Hamra G B, Haylock R, Leuraud K, Moissonnier M et al 2017 The International Nuclear Workers Study (INWORKS): A collaborative epidemiological study to improve knowledge about health effects of protracted low-dose exposure Radiat. Prot. Dosim. 173 21-5 
[17] Gillies M, Richardson D B, Cardis E, Daniels R D, O’Hagan J A, Haylock R, Laurier D, Leuraud K, Moissonnier M, Schubauer-Berigan M et al 2017 Mortality from circulatory diseases and other non-cancer outcomes among nuclear workers in France, the United Kingdom and the United States (INWORKS) Radiat. Res. 188 276-90

[18] Richardson D B, Cardis E, Daniels R D, Gillies M, Haylock R, Leuraud K, Laurier D, Moissonnier M, Schubauer-Berigan M K, Thierry-Chef I et al 2018 Site-specific solid cancer mortality after exposure to ionizing radiation: a cohort study of workers (INWORKS) Epidemiol. 29 31-40

[19] Thierry-Chef I, Richardson D B, Daniels R D, Gillies M, Hamra G B, Haylock R, Kesminiene A, Laurier D, Leuraud K, Moissonnier M et al 2015 Dose estimation for a study of nuclear workers in France, the United Kingdom and the United States of America: methods for the International Nuclear Workers Study Radiat. Res. 183 632-42

[20] Thierry-Chef I, Marshall M, Fix J J, Bermann F, Gilbert E S, Hacker C, Heinmiller B, Murray W, Pearce M S, Utterback D et al 2007 The 15-Country Collaborative Study of cancer risk among radiation workers in the nuclear industry: study of errors in dosimetry Radiat. Res. 167 $380-95$

[21] Napier B A 2017 The Mayak worker dosimetry system (MWDS-2013): an introduction to the documentation Radiat. Prot. Dosim. 176 6-9

[22] Napier B A, Efimov A and Baker S C 2018 The Mayak worker dosimetry system (MWDS2013) for external irradiation Submitted for publication

[23] Vasilenko E K, Khokhryakov V F, Miller S C, Fix J J, Eckerman K, Choe D O, Gorelov M, Khokhryakov V V, Knyasev V, Krahenbuhl M P et al 2007 Mayak worker dosimetry study: an overview Health Phys. 93 190-206

[24] Sokolnikov M, Preston D and Stram D 2017 Mortality from solid cancers other than lung, liver and bone in relation to external dose among plutonium and non-plutonium workers in the Mayak Worker Cohort Radiat. Environ. Biophys. 56 121-25 
[25] Sokolnikov M E, Preston D, Gilbert E, Schonfeld S and Koshurnikova N A 2015 Radiation effects on mortality from solid cancers other than lung, liver, and bone cancer in the Mayak worker cohort: 1948-2008 PLoS One 10 e0117784

[26] Kuznetsova I S, Labutina E V and Hunter N 2016 Radiation risks of leukemia, lymphoma and multiple myeloma incidence in the Mayak cohort: 1948-2004 PLoS One 11 e016271

[27] Zhang Z, Preston D L, Sokolnikov M, Napier B A, Degteva M, Moroz B, Vostrotin V, Shiskina E, Birchall A and Stram D O 2017 Correction of confidence intervals in excess relative risk models using Monte Carlo dosimetry systems with shared errors PLoS One 12 e0174641

[28] Akiba S and Mizuno S 2012 The third analysis of cancer mortality among Japanese nuclear workers, 1991-2001: estimation of excess relative risk per radiation dose J. Radiol. Prot. 32 7383

[29] Zablotska L B, Lane R S D and Thompson P A 2014 A reanalysis of cancer mortality in Canadian nuclear workers (1956-1994) based on revised exposure and cohort data Br. J. Cancer $110214-23$

[30] Boice J D, Jr, Cohen S S, Mumma M T, Ellis E D, Cragle D L, Eckerman K F, Wallace P W, Chadda B, Sonderman J S, Wiggs L D et al 2014 Mortality among Mound workers exposed to Polonium-210 and other sources of radiation, 1944-1979 Radiat. Res. 181 208-28

[31] Boice J D, Jr, Cohen S S, Mumma M T, Ellis E D, Eckerman K F, Leggett R W, Boecker B B, Brill A B and Henderson B E 2011 Updated mortality analysis of radiation workers at Rocketdyne (Atomics International), 1948-2008 Radiat. Res. 176 244-58

[32] Kashcheev V V, Chekin S Y, Maksioutov M A, Tumanov K A, Kochergina E V, Kashcheeva P V, Shchukina N V and Ivanov V K 2015 Incidence and mortality of solid cancer among emergency workers of the Chernobyl accident: assessment of radiation risks for the follow-up period of 1992-2009 Radiat. Environ. Biophys. 54 13-23

[33] Preston D L, Kitahara C M, Freedman D M, Sigurdson A J, Simon S L, Little M P, Cahoon E K, Rajaraman P, Miller J S, Alexander B H et al 2016 Breast cancer risk and protracted low-to- 
[34] Zhivin S, Guseva Canu I, Samson E, Laurent O, Grellier J, Collomb P, Zablotska L B and Laurier D 2016 Mortality (1968-2008) in a French cohort of uranium enrichment workers potentially exposed to rapidly soluble uranium compounds Occup. Environ. Med. $\mathbf{7 3}$ 167-74

[35] Sun Z, Inskip P D, Wang J, Kwon D, Zhao Y, Zhang L, Qin W and Fan S 2016 Solid cancer incidence among Chinese medical diagnostic x-ray workers, 1950-1995: estimation of radiation-related risks Int. J. Cancer 138 2875-83

[36] Caldwell G G, Zack M M, Mumma M T, Falk H, Heath C W, Till J E, Chen H and Boice J.D. J 2016 Mortality among military participants at the 1957 PLUMBBOB nuclear weapons test series and from leukemia among participants at the SMOKY test J. Radiol. Prot. 36 474-89

[37] Boice J D, Jr, Ellis E D, Golden A P, Girardi D J, Cohen S S, Chen H, Mumma M T, Shore R E and Leggett R W 2018 The past informs the future: An overview of the Million Worker Study and the Mallinckrodt Chemical Works cohort Health Phys. 114 381-85

[38] NCRP 2018 Deriving Organ Doses and Their Uncertainty for Epidemiologic Studies (with a focus on the One Million U.S. Workers and Veterans Study of Low-Dose Radiation Health Effects), NCRP Report No. 178 (Bethesda, MD: National Council on Radiation Protection and Measurements)

[39] Bouville A, Toohey R E, Boice J D, Jr, Beck H L, Dauer L T, Eckerman K F, Hagemeyer D, Leggett R W, Mumma M, Napier B et al 2015 Dose reconstruction for the million worker study: status and guidelines Health Phys. 108 206-20

[40] Till J E, Beck H L, Aanenson J W, Grogan H A, Mohler H J, Mohler S S and Voillequé P G 2014 Military participants at U.S. atmospheric nuclear weapons testing-methodology for estimating dose and uncertainty Radiat. Res. 181 471-84

[41] Napier B A 2014 Joint U.S./Russian studies of population exposures resulting from nuclear production activities in the Southern Urals Health Phys. 106 294-304 
[42] Davis F G, Yu K L, Preston D, Epifanova S, Degteva M and Akleyev A V 2015 Solid cancer incidence in the Techa River incidence cohort: 1956-2007 Radiat. Res. 184 56-65

[43] Schonfeld S J, Krestinina L Y, Epifanova S, Degteva M O, Akleyev A V and Preston D L 2013 Solid cancer mortality in the Techa River cohort (1950-2007) Radiat. Res. 179 183-9

[44] Krestinina L Y, Davis F G, Schonfeld S, Preston D L, Degteva M, Epifanova S and Akleyev A V 2013 Leukaemia incidence in the Techa River Cohort: 1953-2007 Br. J. Cancer 109 2886-93

[45] Tronko M D, Howe G R, Bogdanova T I, Bouville A C, Epstein O V, Brill A B, Likhtarev I A, Fink D J, Markov V V, Greenebaum E et al 2006 A cohort study of thyroid cancer and other thyroid diseases after the Chornobyl accident: thyroid cancer in Ukraine detected during first screening J. Natl. Cancer Inst. 98 897-903

[46] Brenner A V, Tronko M D, Hatch M B, T I, Oliynik V A, Lubin J H, Zablotska L B, Tereschenko V P, McConnell R J, Zamotaeva G A, O'Kane P et al 2011 I-131 dose response for incident thyroid cancers in Ukraine related to the Chornobyl accident Environ. Health Perspect. $119933-9$

[47] Zablotska L B, Ron E, Rozhko A V, Hatch M, Polyanskaya O N, Brenner A V, Lubin J, Romanov G N, McConnell R J, O'Kane P et al 2011 Thyroid cancer risk in Belarus among children and adolescents exposed to radioiodine after the Chornobyl accident Br. J. Cancer 104 $181-7$

[48] Lubin J H, Adams M J, Shore R, Holmberg E, Schneider A B, Hawkins M M, Robison L L, Inskip P, Lundell M, Johannson R et al 2017 Thyroid cancer following childhood low dose radiation exposure: a pooled analysis of nine cohorts J. Clin. Endocrinol. Metab. 102 2575-83

[49] Likhtarov I, Kovgan L, Masiuk S, Talerko M, Chepurny M, Ivanova O, Gerasymenko V, Boyko Z, Voilleque' P, Drozdovitch V et al 2014 Thyroid cancer study among Ukrainian children exposed to radiation after the Chornobyl accident: improved estimates of the thyroid doses to the cohort members Health Phys. 106 370-96 
[50] Nair M K, Gangadharan P, Jayalakshmi P, Nair R R K and Mani K S. 2004 Natural background radiation cancer registry. Technical Report 1990-1999. (Trivandrum, Kerala, India: Regional Cancer Center)

[51] Nair R R K, Rajan B, Akiba S, Jayalekshmi P, Nair M K, Gangadharan P, Koga T, Morishima H, Nakamura S and Sugahara T 2009 Background radiation and cancer incidence in Kerala, India - Karunagappally cohort study Health Phys. 96 55-66

[52] Tao Z, Akiba S, Zha Y, Sun Q, Zou J, Li J, Liu Y, Yuan Y, Tokonami S, Morishima H et al 2012 Cancer and non-cancer mortality among inhabitants in the high background radiation area of Yangjiang, China (1979-1998) Health Phys. 102 173-81

[53] UNSCEAR 2013 Effects of radiation exposure of children UNSCEAR Report, Sources, Effects and Risks of Ionizing Radiatio (Scientific Annex B) (New York: United Nations Scientific Committee on the Effects of Ionizing Radiation)

[54] Pearce M S, Salotti J A, Little M P, McHugh K, Lee C, Kim K P, Howe N L, Ronckers C M, Rajaraman P, Craft A W et al 2012 Radiation exposure from CT scans in childhood and subsequent risk of leukaemia and brain tumours: a retrospective cohort study Lancet $\mathbf{3 8 0} 499$ 505

[55] Mathews J D, Forsythe A V, Brady Z, Butler M W, Goergen S K, Byrnes G B, Giles G G, Wallace A B, Anderson P R, Guiver T A et al 2013 Cancer risk in 680000 people exposed to computed tomography scans in childhood or adolescence: data linkage study of 11 million Australians Br. Med.J. 346 f2360

[56] Walsh L, Shore R, Auvinen A, Jung T and Wakeford R 2014 Risks from CT scans--what do recent studies tell us? J. Radiol. Prot. 34 e1-5

[57] Boice J D, Jr 2015 Radiation epidemiology and recent paediatric computed tomography studies Ann. ICRP 44 236-48 
[58] Journy N, Rehel J L, Ducou Le Pointe H, Lee C, Brisse H, Chateil J-F, Caer-Lorho S, Laurier D and Bernier M O 2015 Are the studies on cancer risk from CT biased by indication? Elements of answer from a large-scale cohort study in France Br. J. Cancer 112 185-93

[59] Krille L, Dreger S, Schindel R, Albrecht T, Asmussen M, Barkhausen J, Berthold J D, Chavan A, Claussen C, Forsting M et al 2015 Risk of cancer incidence before the age of 15 years after exposure to ionising radiation from computed tomography: results from a German cohort study Radiat. Environ. Biophys. 54 1-12

[60] Berrington de Gonzaléz A, Salotti J A, McHugh K, Little M P, Harbron R W, Lee C, Ntowe E, Braganza M Z, Parker L, Rajaraman P et al 2016 Relationship between paediatric CT scans and subsequent risk of leukaemia and brain tumours: assessment of the impact of underlyng conditions Br. J. Cancer 114 388-94

[61] Wakeford R 2008 Childhood leukaemia following medical diagnostic exposure to ionizing radiation in utero or after birth Radiat. Prot. Dosim. 132 166-74

[62] Boice J D, Jr. and Miller R W 1999 Childhood and adult cancer following intrauterine exposure to ionizing radiation Teratol. $59227-33$

[63] Preston D, Cullings H, Suyama A, Funamoto S, Nishi N, Soda M, Mabuchi K, Kodama K, Kasagi F and Shore R E 2008 Solid cancer incidence in atomic bomb survivors exposed in utero or as young children J. Natl. Cancer Inst. 100 428-36

[64] ICRP 2012 ICRP statement on tissue reactions and early and late effects of radiation in normal tissues and organs--threshold doses for tissue reactions in a radiation protection context. (Publication 118) Ann. ICRP 41 1-322

[65] NCRP 2016 Guidance on Radiation Dose Limits for the Lens of the Eye, Commentary No. 26 (Bethesda, MD: National Council on Radiation Protection and Measurements)

[66] Shore R E 2016 Radiation and cataract risk: Impact of recent epidemiologic studies on ICRP judgments Mutat. Res: Rev. Mutat. Res. 770 231-37 
[67] UNSCEAR 2015 Uncertainties in risk estimates for radiation induced cancer United Nations Sources and Effects of Atomic Radiation, UNSCEAR 2012 Report (Scientific Annex B) (New York: United Nations Scientific Committee on the Effects of Ionizing Radiation)

[68] Stram D O, Preston D L, Sokolnikov M, Napier B, Kopecky K J, Boice J D, Beck H, Till J and Bouville A 2015 Shared dosimetry error in epidemiological dose-response analyses PLoS One $10 \mathrm{e} 0119418$

[69] Kwon D, Hoffman F O, Moroz B E and Simon S L 2016 Bayesian dose-response analysis for epidemiological studies with complex uncertainty in dose estimaton Statist. Med. 35 399-423

[70] Rühm W, Eidemüller M and Kaiser J C 2017 Biologically-based mechanistic models of radiation-related carcinogenesis applied to epidemiological data Int. J. Radiat. Biol. 93 1093117

[71] Preston R J 2017 Can radiation research impact the estimation of risk? Int. J. Radiat. Biol. 93 $1009-14$

[72] Jacob P, Rühm W, Walsh L, Blettner M, Hammer G and Zeeb H 2009 Cancer risk of radiation workers larger than expected? Occup. Environ. Med. 66 789-96

[73] Daniels R D and Schubauer-Berigan M K 2011 A meta-analysis of leukaemia risk from protracted exposure to low-dose gamma radiation Occup. Environ. Med. 68 457-64

[74] Boice J D, Jr. A study of one million U.S. radiation workers and veterans a new NCRP initiative. Health Phys. News [serial on the Internet]. 2012; (The Boice Report No. 06): Available from: http://ncrponline.org/the-boice-report/.

[75] Rybkina V L, Bannikova M V, Adamova G V, Dörr H, Scherthan H and Azizova T V 2018 Immunological markers of chronic occupational radiation exposure Health Phys. 115 108-13

[76] Hunter N, Kuznetsova I S, Labutina E V and Harrison J D 2013 Solid cancer incidence other than lung, liver and bone in Mayak workers: 1948-2004 Br. J. Cancer 109 1989-96 
[77] Howe G R, Zablotska L B, Fix J J and Egel J B, J 2004 Analysis of the mortality experience amongst U.S. nuclear power industry workers after chronic low-dose exposure to ionizing radiation Radiat. Res. 162 517-26

[78] Kreuzer M, Dufey F, Laurier D, Nowak D, Marsh J W, Schnelzer M, Sogl M and Walsh L 2015 Mortality from internal and external radiation exposure in a cohort of male German uranium millers, 1946-2008 Int. Arch. Occup. Environ. Health 88 431-41

[79] Zablotska L B, Lane R S and Frost S E 2013 Mortality (1950-1999) and cancer incidence (1969-1999) of workers in the Port Hope cohort study exposed to a unique combination of radium, uranium and gamma-ray doses BMJ Open $\mathbf{3}$ e002159

[80] Muirhead C R, O'Hagan J A, Haylock R G E, Phillipson M A, Willcock T, Berridge G L C and Zhang W 2009 Mortality and cancer incidence following occupational radiation exposure: third analysis of the National Registry for Radiation Workers Br. J. Cancer 100 206-12

[81] Kendall G M, Little M P, Wakeford R, Bunch K J, Miles J C H, Vincent T J, Meara J R and Murphy M F G 2013 A record-based case-control study of natural background radiation and the incidence of childhood leukaemia and other cancers in Great Britain during 1980-2006 Leukemia 27 3-9

[82] Zablotska L B, Bazyka D, Lubin JH, Gudzenko N, Little M P, Hatch M, Finch S, Dyagil I R, R F, Chumak V V, Bouville A et al 2013 Radiation and the risk of chronic lymphocytic and other leukemias among Chornobyl cleanup workers Environ. Health Perspect. 121 59-65

[83] Kreuzer M, Sobotzki C, Fenske N, Marsh J W and Schnelzer M 2017 Leukaemia mortality and low-dose ionising radiation in the WISMUT uranium miner cohort (1946-2013) Occup. Environ. Med. 74 252-58

[84] NCRP 2001 Evaluation of the linear-nonthreshold dose-response model for ionizing radiation NCRP Report No. 136 (Bethesda, MD: National Council on Radiation Protection and Measurements) 
[85] ICRP 2005 Low-dose extrapolation of radiation-related cancer risk ICRP Publication No. 99 Ann. ICRP 35 1-141

[86] ICRP 2007 The 2007 Recommendations of the International Commission on Radiological Protection ICRP Publication 103 (Annex A. Biological and epidemiological information on health risks attributable to ionising radiation) Ann. ICRP 37 137-246

[87] Little M P and Boice J D, Jr 2003 Analysis of breast cancer in the Massachusetts TB fluoroscopy cohort and in the Japanese A-bomb survivors, taking account of dosimetric error and curvature in the A-bomb dose response: absence of evidence of reduction in risk following fractionated irradiation Int. J. Low Radiat. 1 88-101

[88] Eidemüller M, Holmberg E, Jacob P, Lundell M and Karlsson P/2015 Breast cancer risk and possible mechanisms of radiation-induced genomic instability in the Swedish hemangioma cohort after reanalyzed dosimetry Mutation Research/Fundamental and Molecular Mechanisms of Mutagenesis $\mathbf{7 7 5}$ 1-9

[89] Liu J J, Freedman D M, Little M P, Doody M M, Alexander B H, Kitahara C M, Lee T, Rajaraman P, Miller J S, Kampa D M et al 2014 Work history and mortality risks in 90268 US radiological technologists Occup. Environ. Med. 71 819-35

[90] Hsieh W-H, Lin I-F, Ho J-C and Chang P W 201730 years follow-up and increased risks of breast cancer and leukaemia after long-term low-dose-rate radiation exposure Br. J. Cancer 117 $1883-87$

[91] Akleyev A V, Deltour I, Krestinina L, Sokolnikov M, Tsareva Y, Tolstykh E and Schüz J 2016 Incidence and mortality of solid cancers in people exposed in utero to ionizing radiation: Pooled analyses of two cohorts from the Southern Urals, Russia PLoS One 11 e0160372

[92] Davis S, Kopecky K J, Hamilton T E, Onstad L and Hanford Thyroid Disease Study Team 2004 Thyroid neoplasia, autoimmune thyroiditis, and hypothyroidism in persons exposed to iodine 131 from the Hanford Nuclear Site J. Am. Med. Assoc. 292 2600-13

[93] Little J Ionizing radiation 1999 (Lyon, France: International Agency for Research on Cancer) 
[94] Lyon J L, Alder S C, Stone M B, Scholl A, Reading J C, Holubkov R, Sheng X, White Jr G L, Hegmann K T, Anspaugh L et al 2006 Thyroid disease associated with exposure to the Nevada Nuclear Weapons Test Site radiation Epidemiol. 17 604-14

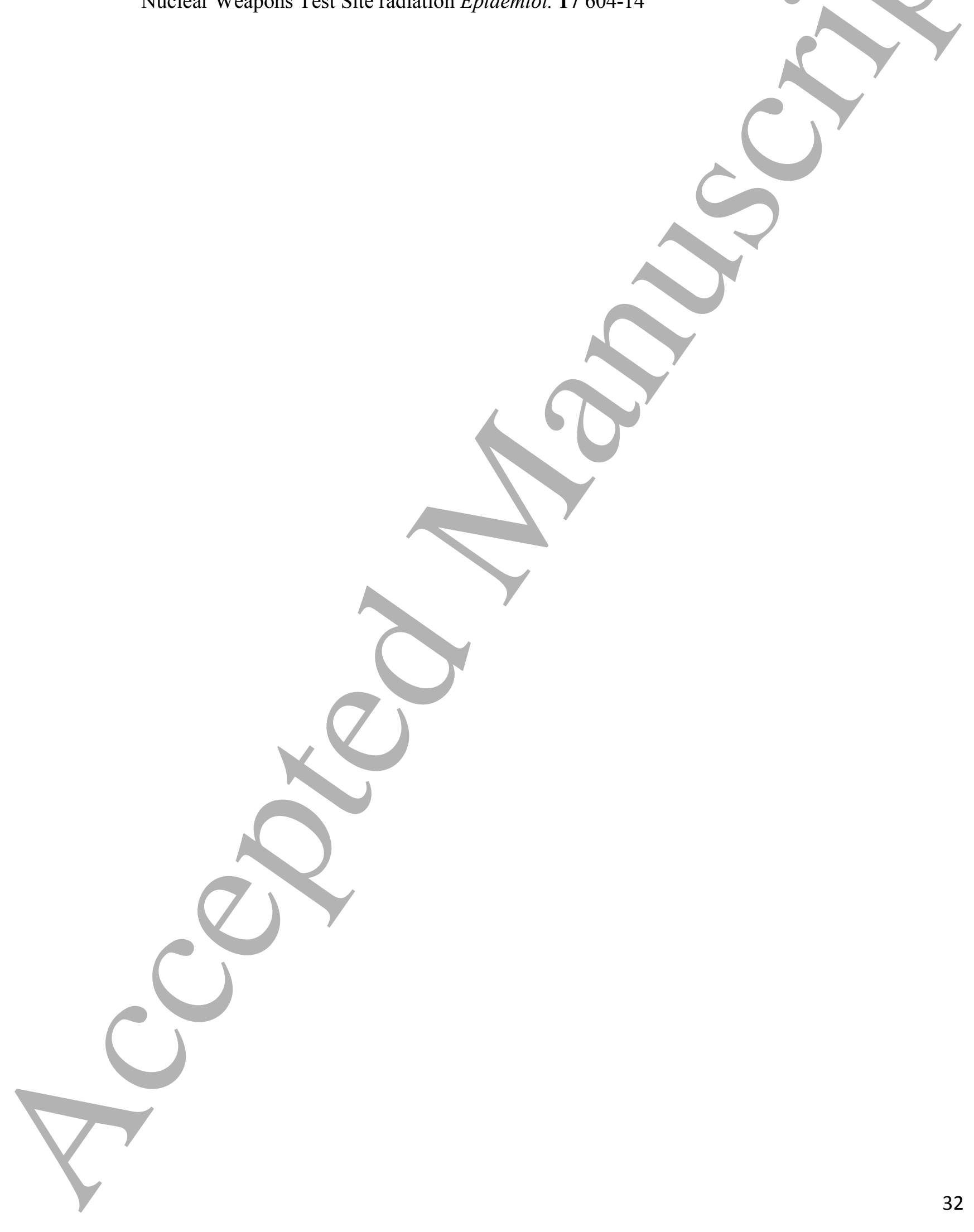


Table 1-Rated strength of support for the LNT model for use in radiation protection by studies of radiation exposure and cancer

Studies (or groups of studies) and representative publications ${ }^{a, b, c}$

Life Span Study (LSS), Japan atomic bombs [9]

INWORKS (U.K., U.S., French combined cohorts) [13]

Tuberculosis fluoroscopic examinations and breast cancer [87]

Childhood Japan atomic bomb exposure [63]

Childhood thyroid cancer studies [48]

Mayak nuclear workers [25]

Chernobyl fallout, Ukraine and Belarus thyroid cancer [46]

Moderate

Breast cancer studies, after childhood exposure [88]

Moderate

In utero exposure, Japan atomic bombs [63]

Moderate

Techa River, nearby residents [43]

Moderate $^{\mathrm{d}}$

In utero exposure, medical [61]

Moderate $^{\mathrm{d}}$

Japan nuclear workers [28]

Weak-to-moderate

Chernobyl cleanup workers, Russia [32]

U.S. radiologic technologists $[33,89]$

Mound nuclear workers [30]

Weak-to-moderate

Rocketdyne nuclear workers [31]

Weak-to-moderate

French uranium processing workers [34]

Weak-to-moderate

Medical x-ray workers, China [35]

Weak-to-moderate ${ }^{\mathrm{e}}$

Taiwan radiocontaminated buildings, residents [90]

Weak-to-moderate ${ }^{\mathrm{e}}$

Background radiation levels and childhood leukemia [81]

Weak-to-moderate 
In utero exposures, Mayak and Techa [91]

Hanford ${ }^{131}$ I fallout study [92]

Kerala, India, high natural background radiation area [51]

Canadian worker study [29]

U.S. atomic veterans [36]

Yangjiang, China, high natural background radiation area [52]

CT examinations of young persons [54]

Childhood medical $\mathrm{x}$ rays and leukemia (aggregate of $>10$ studies) [61, 93]

Nuclear weapons test fallout studies (aggregate of eight studies) [94]
No support

No support

No support

No support

No support

Inconclusive $^{\mathrm{e}}$

Inconclusive $^{\mathrm{e}}$

Inconclusive $^{\mathrm{e}}$

Inconclusive $^{\mathrm{e}}$

${ }^{a}$ Study ratings were based on reported solid cancer (or close surrogates) risk unless noted otherwise.

${ }^{\mathrm{b}}$ A representative recent publication is listed for each study or study group. Others are found in the text.

${ }^{\mathrm{c}}$ A number of studies were excluded for various reasons, including but are not limited to: ecological studies of residents around nuclear power plant facilities, studies of hereditary effects, studies of tissue reaction (or "deterministic") effects, and the 15-Country study and other studies that overlap with the more recent INWORKS study.

'Considered borderline between "Moderate" and "Weak-to-Moderate" support for the LNT model.

e Considered "weak" support or "inconclusive" primarily because of weaknesses in epidemiology, dosimetry or statistical risk modeling. The studies listed as "No support" had reasonable methodologies but provided little or no support for the LNT model because their risk coefficients were essentially zero or negative. 